\title{
Percepções de Licenciandos em Ciências Biológicas sobre a disciplina de Genética e a
} adaptação ao ensino remoto

\author{
Biological Science Bachelor's perceptions about the subject of Genetics and adaptation to remote \\ education
}

Percepciones del Licenciados en Ciencias Biológicas sobre el tema de Genética y la adaptación a la educación a distancia

Recebido: 10/07/2021 | Revisado: 16/07/2021 | Aceito: 17/07/2021 | Publicado: 26/07/2021

\author{
José Ericson Lima dos Santos \\ ORCID: https://orcid.org/0000-0002-9852-9222 \\ Instituto Federal de Educação, Ciência e Tecnologia do Piauí, Brasil \\ E-mail: ericson.alvo@gmail.com \\ Karoene da Silva Castro \\ ORCID: https://orcid.org/0000-0003-2845-8198 \\ Instituto Federal de Educação, Ciência e Tecnologia do Piaú, Brasil \\ E-mail: karoenes.c@gmail.com \\ Ícaro Fillipe de Araújo Castro \\ ORCID: https://orcid.org/0000-0003-1808-9157 \\ Instituto Federal de Educação, Ciência e Tecnologia do Piauí, Brasil \\ E-mail: icaro.castro@ifpi.edu.br
}

\begin{abstract}
Resumo
A doença do novo coronavírus exigiu mudanças em todas as áreas da sociedade, obrigando todos os países a se adaptarem à nova realidade. O combate ao vírus impôs a necessidade do isolamento social, e o ensino remoto se mostrou como a única maneira de atender às demandas educacionais mundiais. Apesar de aliado, observa-se ainda certa dificuldade na discussão de assuntos complexos por meio do ensino remoto, como, por exemplo, os conteúdos de Genética. O objetivo deste trabalho foi conhecer as percepções dos Licenciandos em Ciências Biológicas de uma Instituição Federal de Ensino Superior relacionada à Genética, bem como sua discussão por meio do ensino remoto. A referida pesquisa possui natureza observacional, com abordagem quali-quantitativa. Quanto aos objetivos, classifica-se como exploratória e quanto aos procedimentos técnicos, como pesquisa de campo. Todos os participantes concordaram com um Termo de Consentimento Livre e Esclarecido (TCLE) e responderam a um questionário semiestruturado, confeccionado por meio da ferramenta Google Forms. Os resultados apontam dificuldades diversas relacionadas ao ensino-aprendizagem da Genética, principalmente por deficiência no debate desses conteúdos na Educação Básica e complexidades de termos técnicos inerentes à disciplina. Tais percalços se acentuam no período remoto atualmente vivenciado, principalmente pela dificuldade na realização de aulas práticas, bem como a implementação de projetos que permitam melhor contextualização da disciplina Genética. Dessa forma, enfatizamos a necessidade da realização de mais estudos que apontem a influência do ensino remoto na formação de docentes brasileiros e dos seus reflexos na qualidade de ensino na Educação Básica.
\end{abstract}

Palavras-chave: Ensino de biologia; Formação de professores; Ensino de genética.

\begin{abstract}
The coronavirus disease required changes in all areas of the world society, forcing all countries to adapt to the new reality. Fighting the virus imposed the need for social isolation, and remote learning became known as the only way to meet the world's educational demands. Even though it's an ally, there is still a certain difficulty in dealing with complex issues through remote learning, such as, for example, Genetics contents. This work aimed to know the perceptions of Undergraduates in Biological Sciences of a Federal Institution of Higher Education related to Genetics, as well as its approach through remote teaching. The purchase has an observational nature, with a quali-quantitative approach. As for the objectives, it is classified as exploratory and as for the technical procedures, as field research. The participants agreed to a Free and Informed Consent Form (TCLE) and answered a semi-structured questionnaire, prepared using the Google Forms tool. The results point out different difficulties related to the teaching-learning of Genetics, mainly due to a deficiency in the discussion of these contents in Basic Education and complexities of technical terms inherent to the discipline. Such mishaps are accentuated in the remote period currently experienced, mainly due to the difficulty in conducting practical classes, as well as the implementation of projects that occur in a better contextualization of the Genetics discipline. Thus, we emphasize the need to conduct more studies that mention
\end{abstract}


the influence of remote education in the training of Brazilian teachers and its effects on the quality of teaching in Basic Education.

Keywords: Biology teaching; Teacher training; Teaching of genetics.

\begin{abstract}
Resumen
La nueva enfermedad del coronavirus requirió cambios en todos los ámbitos de la sociedad, lo que obligó a todos los países a adaptarse a la nueva realidad. La lucha contra el virus impuso la necesidad de aislamiento social, y el aprendizaje a distancia demostró ser la única forma de satisfacer las demandas educativas del mundo. A pesar de ser un aliado, todavía existe cierta dificultad para discutir temas complejos a través del aprendizaje a distancia, como, por ejemplo, los contenidos de Genética. El objetivo de este trabajo fue conocer las percepciones de los Licenciados en Ciencias Biológicas de una Institución Federal de Educación Superior relacionada con la genética, así como su discusión a través de la enseñanza a distancia. La compra tiene un carácter observacional, con un enfoque cualicuantitativo. En cuanto a los objetivos, se clasifica como exploratorio y en cuanto a los procedimientos técnicos, como investigación de campo. Los participantes aceptaron un Formulario de Consentimiento Libre e Informado (TCLE) y respondieron un cuestionario semiestructurado, elaborado con la herramienta Google Forms. Los resultados señalan diferentes dificultades relacionadas con la enseñanza-aprendizaje de la genética, principalmente por deficiencias en el debate de estos contenidos en Educación Básica y complejidades de términos técnicos inherentes a la disciplina. Dichos percances se acentúan en el remoto período que se vive actualmente, principalmente por la dificultad para realizar las clases prácticas, así como la implementación de proyectos que permitan una mejor contextualización de la disciplina genética. Así, enfatizamos la necesidad de realizar más estudios que señalen la influencia de la educación a distancia en la formación de docentes brasileños y sus efectos en la calidad de la enseñanza en Educación Básica.
\end{abstract}

Palabras clave: Enseñanza de la biología; Formación de profesores; Enseñanza de la genética.

\title{
1. Introdução
}

A pandemia relacionada ao novo coronavírus trouxe impactos diversos ao mundo, obrigando os indivíduos a uma nova rotina de vida, que tem como pilares os cuidados com a higiene pessoal e o isolamento social. Por isso, muitos países, como por exemplo, o Brasil, adotaram medidas restritivas, inclusive, no campo educacional, principalmente, estimulando as atividades educacionais de forma não presencial (Brasil, 2020ª).

A portaria n ${ }^{\circ} 544$ de 16 de junho de 2020, publicada no Diário Oficial da União (DOU), estendeu a autorização para as atividades remotas até 31 de dezembro de 2020, bem como atribuiu, às Instituições de Ensino, a definição dos componentes curriculares, a disponibilização de recursos aos discentes e a realização de avaliações (Brasil, 2020 ${ }^{\text {b }}$. Dessa forma, esse efeito tornou obrigatório que alguns professores se tornassem youtubers, inserindo-se em um ambiente educacional on-line e adotando novas práticas pedagógicas em suas ações educativas (Moreira, Henriques \& Barros, 2020).

O grande desafio para os docentes e especialistas da educação é como adentrar em um ambiente on-line e ministrar aulas complexas de forma remota, em tempo reduzido e com a manutenção da qualidade no ensino. Nesse cenário, destaca-se a utilização das Tecnologias de Informação e Comunicação (TICs), que foram adotadas por várias instituições de ensino, utilizando-se de ambientes virtuais de aprendizado (AVA), bem como de adaptações para a modalidade do Ensino a Distância (EAD) (Cordeiro, 2020).

Apesar de o ensino remoto permitir o prosseguimento dos estudos em tempos de isolamento social, muitos alunos não conseguiram se adaptar a essa nova modalidade de ensino, seja pela dificuldade na flexibilização do tempo, na quebra da rotina de estudos ou pela ausência de uma internet de qualidade que contribua para o êxito na aprendizagem (Lima et al., 2020). Destacam-se também a ausência do contato pessoal com colegas e alunos (Reis, Rocha \& Silva, 2020) e a não sinergia dos alunos com as plataformas digitais disponíveis (Silva \& Júnior, 2021).

Essas dificuldades se acentuam em disciplinas que já são comumente consideradas difíceis, como, por exemplo, a disciplina de Genética, obrigatória em cursos de Licenciatura em Ciências Biológicas e conteúdo fundamental nas disciplinas Ciências e Biologia, discutido no nono ano do Ensino Fundamental e terceiro ano do Ensino Médio, respectivamente. Para muitos, possui termos complexos de difícil entendimento, principalmente, em função de suas especificidades (Santos et al., 
2020), vocabulário específico e com inúmeros conceitos (Santos, 2018), bem como as dificuldades na interpretação de questões ou resolução de seus cálculos (Araújo et al., 2018).

A ciência da Genética é basicamente um elo na tradução de informações em que geneticistas encontram respostas para diversos mecanismos, como transmissão da informação entre indivíduos genitores e descendentes, respostas para a evolução das espécies (Griffiths et al., 2016), a elaboração de vacinas para determinadas doenças, o conhecimento sobre genes defeituosos (Furtado, 2019; Lander et al., 2019) e outras inúmeras biotecnologias que melhoram a qualidade de vida humana e que precisam ser entendidas e discutidas pela sociedade.

Tendo em vista a importância da formação adequada de Licenciandos em Ciências Biológicas, bem como os reflexos dessa formação para qualidade do processo de ensino aprendizagem na Educação Básica, destacamos a disciplina de Genética como fundamental na formação de professores de Ciências e Biologia, e que suas estratégias metodológicas e as dificuldades associadas ao seu aprendizado devem ser discutidas e servirem de parâmetro para o aprimoramento e a melhora da disciplina.

Por isso, esse trabalho teve como objetivo geral conhecer as percepções de Licenciandos em Ciências Biológicas do Instituto Federal de Educação, Ciência e Tecnologia do Piauí (IFPI-Uruçuí) sobre a disciplina de Genética, assim como sua discussão por meio do ensino remoto. Dentre os objetivos específicos, destacamos: relatar as principais metodologias utilizadas para o debate de conteúdos de Genética no Ensino Superior em tempos de pandemia, bem como descrever as percepções dos Licenciandos sobre as principais dificuldades associadas ao aprendizado da Genética na Educação Básica e na Educação Superior.

\section{Metodologia}

A referida pesquisa possui natureza observacional, com abordagem quali-quantitativa. Quanto aos objetivos, classifica-se como exploratória e quanto aos procedimentos técnicos, como pesquisa de campo (Fontelles et al., 2009). Para a realização desta pesquisa, inicialmente, aconteceu o contato com diretor do IFPI, Campus Uruçuí, e foi apresentada a proposta para realização do referido estudo. A partir da anuência do gestor, realizou-se o contato com os discentes da disciplina Genética, cursada no segundo semestre de 2020, único momento que a disciplina foi ofertada de forma remota, até então.

Todo o contato com os Licenciandos em Ciências Biológicas ocorreu de forma remota, respeitando as orientações de distanciamento social da Organização Mundial de Saúde (OMS). Após o esclarecimento de pontos fundamentais da pesquisa, os discentes foram convidados a participar da pesquisa, e a sua concordância se deu por meio de um Termo de Consentimento Livre e Esclarecido (TCLE), que garantia ao participante total anonimato e retirada de seus dados da pesquisa a qualquer momento anterior à publicação, além da publicação dos resultados em meios científicos.

Após o aceite, os participantes receberam um link via WhatsApp, contendo um formulário confeccionado pela ferramenta Google Forms. O método de coleta de informações via link a redes sociais é uma importante ferramenta de pesquisa, principalmente, em tempos de isolamento social, pois permite alcançar um maior número de participantes e garante o anonimato das respostas, sem a influência das opiniões dos pesquisadores (Pereira, Godoy \& Tercariol, 2009).

O questionário utilizado foi baseado no trabalho de Castro et al. (2020), sendo do tipo semiestruturado e composto por 13 questões (apêndice), das quais: duas caracterizaram o perfil dos participantes, cinco perguntas foram relacionadas ao ensino remoto e seis, relacionadas ao ensino de Genética. As respostas referentes às perguntas objetivas foram analisadas com ênfase nas porcentagens para cada alternativa, e as respostas de algumas questões foram também representadas por meio de gráficos confeccionados pelo programa Excel (2013). Para as questões abertas, utilizou-se o método da análise de conteúdo utilizado para a categorização das respostas (Ferreira \& Loguecio, 2014). 


\section{Resultados e Discussão}

Dentre os 26 participantes desta pesquisa, 18 pertenciam ao sexo feminino, sete ao sexo masculino, e um participante não identificou o sexo. A média de idade predominante, representada por 24 pessoas, foi de indivíduos entre 18 e 25 anos. $\mathrm{O}$ estudo também contou com a participação de um aluno com idade entre 26 e 30 anos, e um aluno com idade superior a 30 anos.

Na terceira questão, indagou-se aos participantes sobre suas perspectivas relacionadas à adaptação ao ensino remoto. A partir das respostas, observou-se que 19 participantes (73\%) tiveram dificuldades para se acostumar com a nova rotina, mas que a adaptação está acontecendo, enquanto cinco participantes (19\%) relataram que ainda não conseguiram se adaptar. Dois participantes $(8 \%)$ apontaram facilidade na adaptação ao ensino remoto. A representação gráfica das respostas dos discentes pode ser observada na Figura 1.

Flores et al. (2021), ao realizarem um estudo relacionado ao ensino remoto com diversas universidades no país, perceberam que a maioria dos alunos entrevistados $(38,6 \%)$ não se adaptou a essa nova modalidade, evidenciando algumas dificuldades, como: falta de concentração por estar estudando em casa, extinção de aulas práticas, falta de cooperação entre os colegas e mudança abrupta na rotina de estudos. Por outro lado, os mesmos autores observaram que 37,5\% dos pesquisados tiveram boa adaptação ao ensino remoto.

Figura 1. Representação gráfica das respostas dos participantes da pesquisa em relação à sua adaptação às aulas remotas.

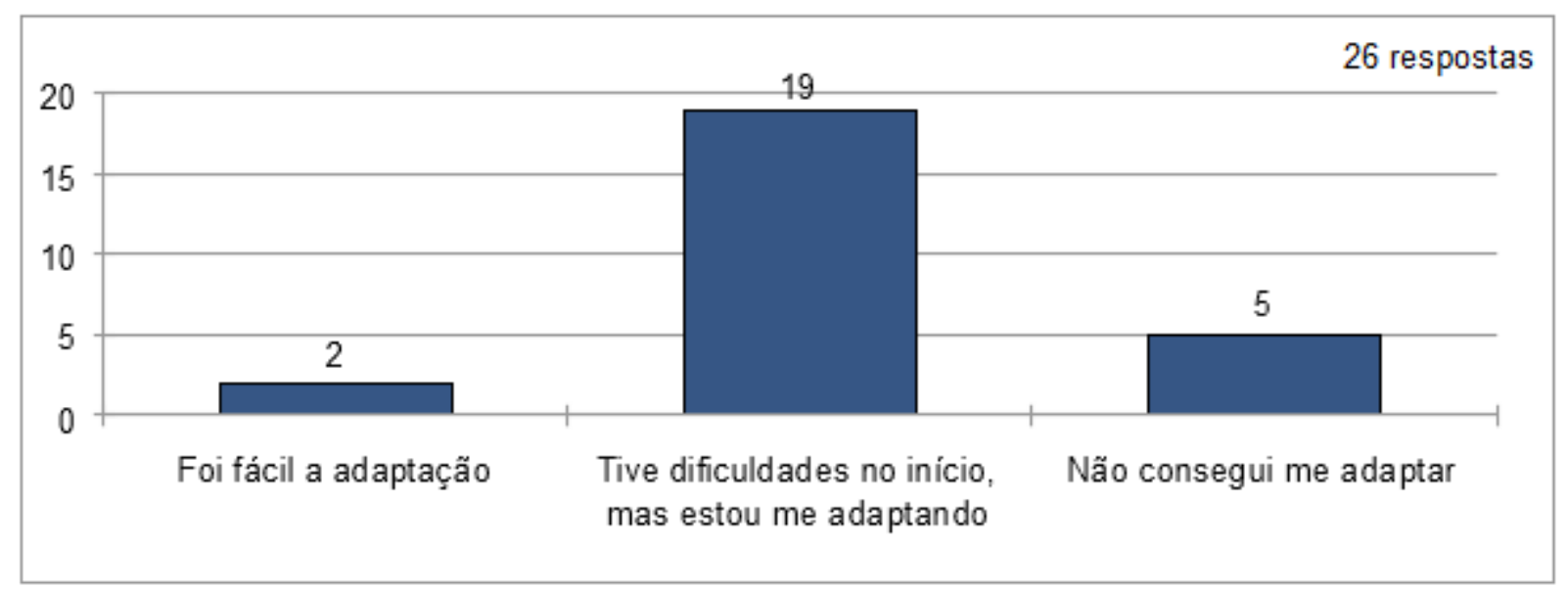

Fonte: Acervo pessoal do autor (2021).

A quarta questão indagou aos participantes sobre os métodos avaliativos utilizados pelos docentes das diversas disciplinas aplicadas de forma remota. Entre as respostas, 18 participantes (69\%) consideraram os métodos de avaliação diversos. Cinco participantes (19\%) afirmam que esses métodos se baseiam em metodologias ativas, e três respondentes (12\%) consideram os métodos de avaliação tradicional, como observado na Figura 2.

Menezes (2021) reforça que não há uma abordagem ideal e ímpar a ser seguida. As estratégias de ensino exigidas no cenário atual, impõem ao professor a procura da variabilidade em estratégias voltadas à avaliação do aluno, e que os conteúdos ministrados devem ser norteados em face ao perfil do discente, para o êxito na aprendizagem. Gonçalves (2020), ao realizar um estudo com objetivo de avaliar os principais problemas que dificultam a aprendizagem na disciplina de Genética, com Licenciandos em Ciências Biológicas, da Universidade Federal de Campina Grande, concluiu que provas escritas são ótimos instrumentos avaliativos, mas que é necessária a inserção de formas alternativas de avaliação que ofereçam diagnósticos precisos e supram as limitações das avaliações tradicionais. 
Figura 2. Representação gráfica das respostas dos participantes da pesquisa em relação às avaliações realizadas pelos professores.

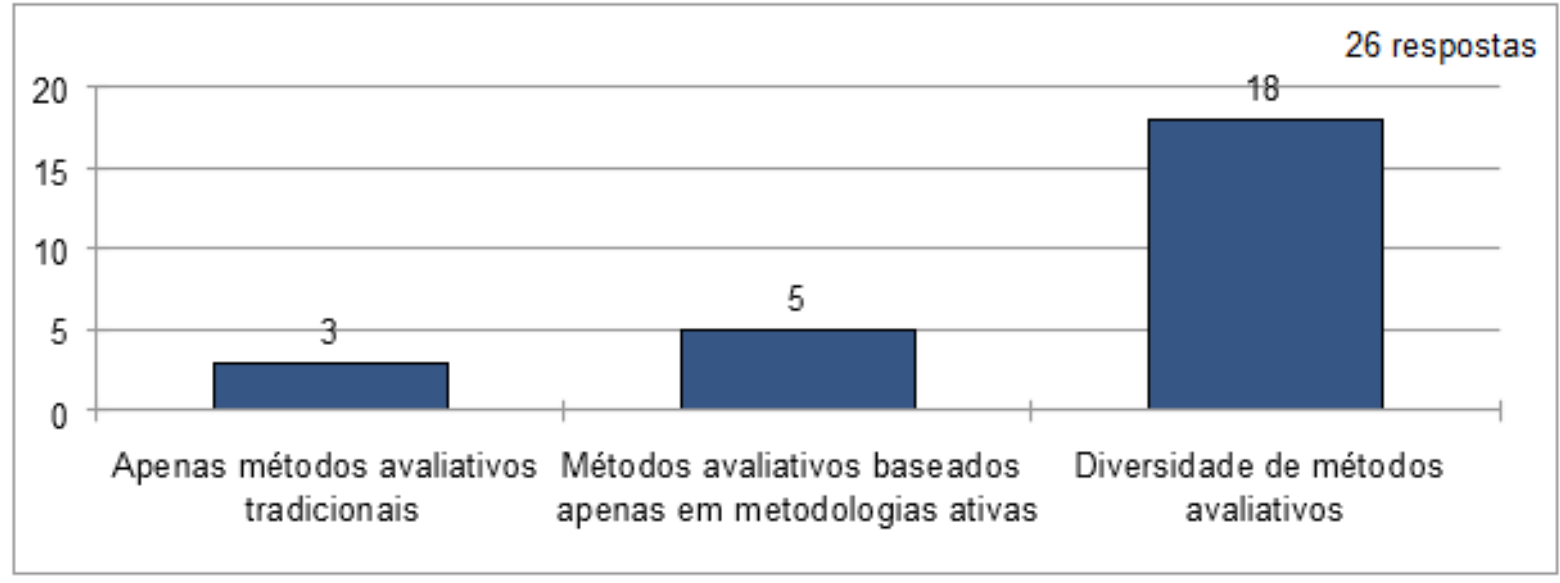

Fonte: Acervo pessoal do autor (2021).

$\mathrm{Na}$ quinta questão, a pesquisa buscava relatar a perspectiva dos participantes em relação ao seu desempenho acadêmico durante o período remoto. Nas respostas, 13 (50\%) declaram que o desempenho foi prejudicado, tendo uma maior dificuldade com os conteúdos disponibilizados, 11 participantes (42\%) não perceberam mudanças no seu desempenho nas aulas remotas, e dois participantes $(7 \%)$ responderam que o seu desempenho foi otimizado no período remoto, com bom aproveitamento dos conteúdos ministrados, como observado na Figura 3.

Dosea et al. (2020) destacam que a falta de familiaridade às plataformas oferecidas ao aluno para a aprendizagem se mostra como uma barreira para um melhor aproveitamento do ensino remoto, e que esse problema é potencializado pela incapacidade ou inexistência de preparação das instituições de ensino. Ainda para os autores, esses fatores impedem um aprendizado exitoso aos discentes, observado na resposta de 47\% dos alunos de Ensino Superior, participantes do referido trabalho.

Figura 3. Representação gráfica das respostas dos participantes da pesquisa em relação ao seu desempenho acadêmico no período remoto.

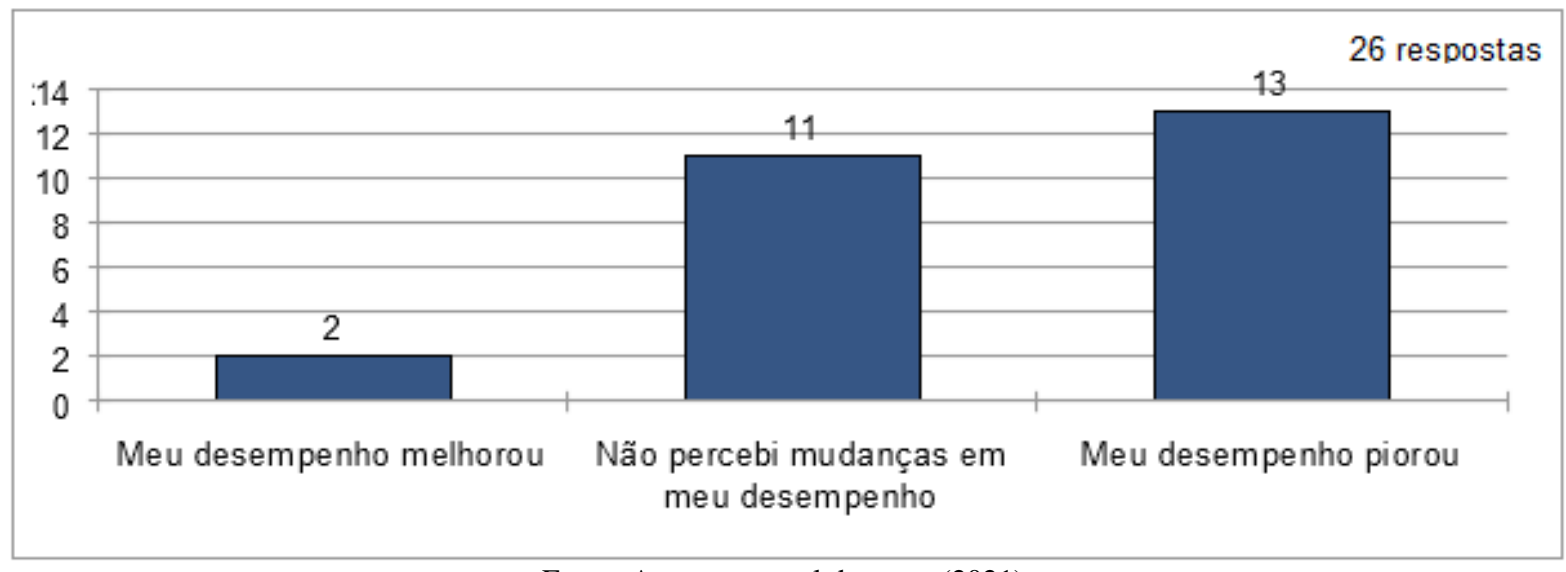

Fonte: Acervo pessoal do autor (2021).

Na pergunta seis, os estudantes puderam responder se recomendariam a continuação do ensino remoto para alguma disciplina em período posterior à pandemia. Nas respostas, 12 alunos $(46,15 \%)$ não associariam as duas formas de ensino, alegando que o ensino remoto é muito complicado, $10(38,46 \%)$ não possuem opinião formada a respeito, e quatro (15,39\%) acreditam que seria eficaz e interessante alinhar o ensino remoto ao presencial, como observado na Figura 4. 
Um estudo realizado por Castro et al. (2021), em uma Instituição Federal de Ensino pernambucana, evidenciou que a maioria dos Licenciandos em Ciências Biológicas participantes da pesquisa (54,5\%) não associou o ensino remoto ao presencial, pois o julgam muito complicado, sendo difícil conciliar as duas modalidades em um período pós-pandemia.

Figura 4. Representação gráfica das respostas dos participantes da pesquisa em relação à continuação do ensino remoto de forma concomitante ao presencial.

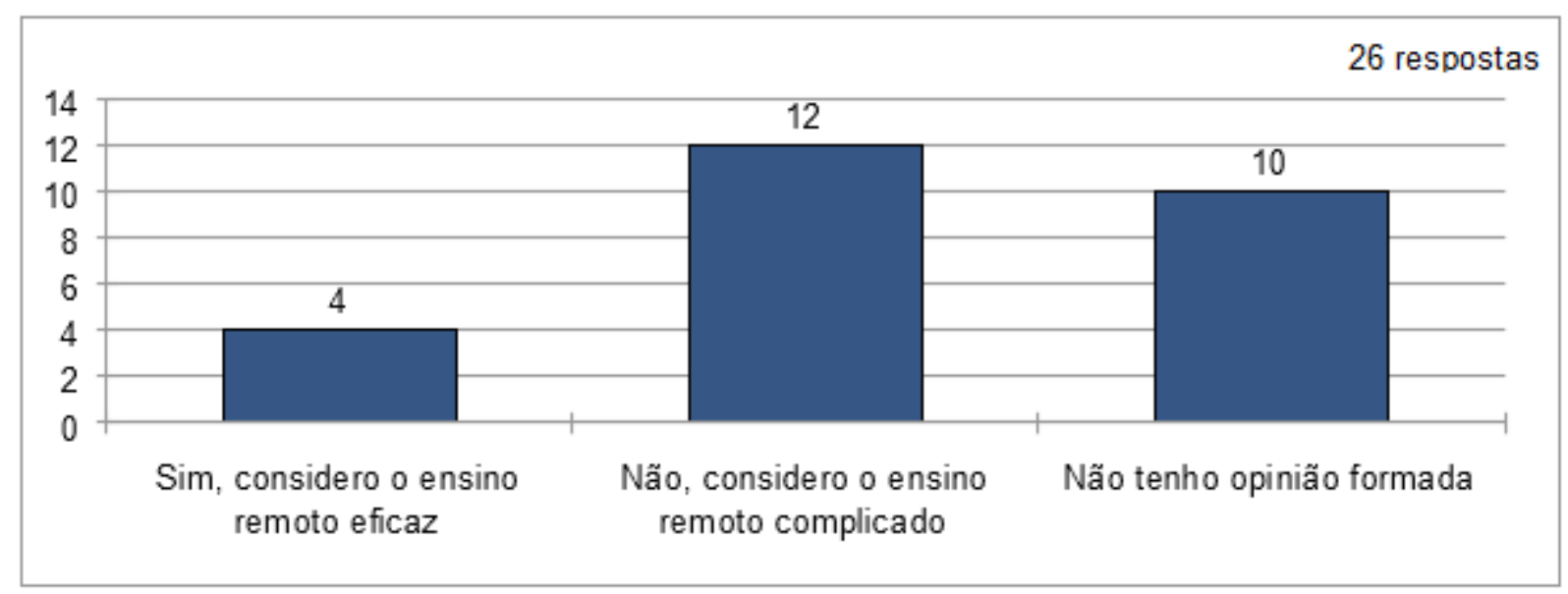

Fonte: Acervo pessoal do autor (2021).

A sétima questão se caracterizava como subjetiva e solicitou que os participantes do estudo elencassem a principal dificuldades observadas por eles durante o período remoto até o momento da aplicação da pesquisa. Para melhor compreensão, foi realizada uma análise de conteúdo e as respostas foram distribuídas em sete categorias. Nas respostas, cinco participantes (19\%) apontaram a alternativa sem dificuldades; dois (8\%) relataram falta de motivação; nove (35\%) indicaram dificuldades com meios tecnológicos; quatro (15\%) destacam a falta de contato presencial com o professor; um aluno (4\%) aponta ambiente inadequado para estudos; quatro (15\%) destacam dificuldade em se concentrar, e um aluno (4\%) destacou a inabilidade dos docentes frente às tecnologias digitais, como observado na figura cinco.

Autores diversos também relatam barreiras e dificuldades dos discentes ao ensino remoto. Feitosa et al. (2020) observaram, em seu trabalho, baixa produtividade dos discentes, bem como falta de estímulo para realizar as atividades acadêmicas. Outro ponto de dificuldade, frequentemente observado, é a pouca interação entre professor e aluno que ocorreria se fosse no ensino presencial. Outro ponto de dificuldade, frequentemente relatado, é a pouca interação entre docentes e discentes (Durão \& Raposo, 2020; Feitosa et al., 2020). 
Figura 5. Representação gráfica das principais dificuldades apontadas pelos participantes para com o ensino remoto.

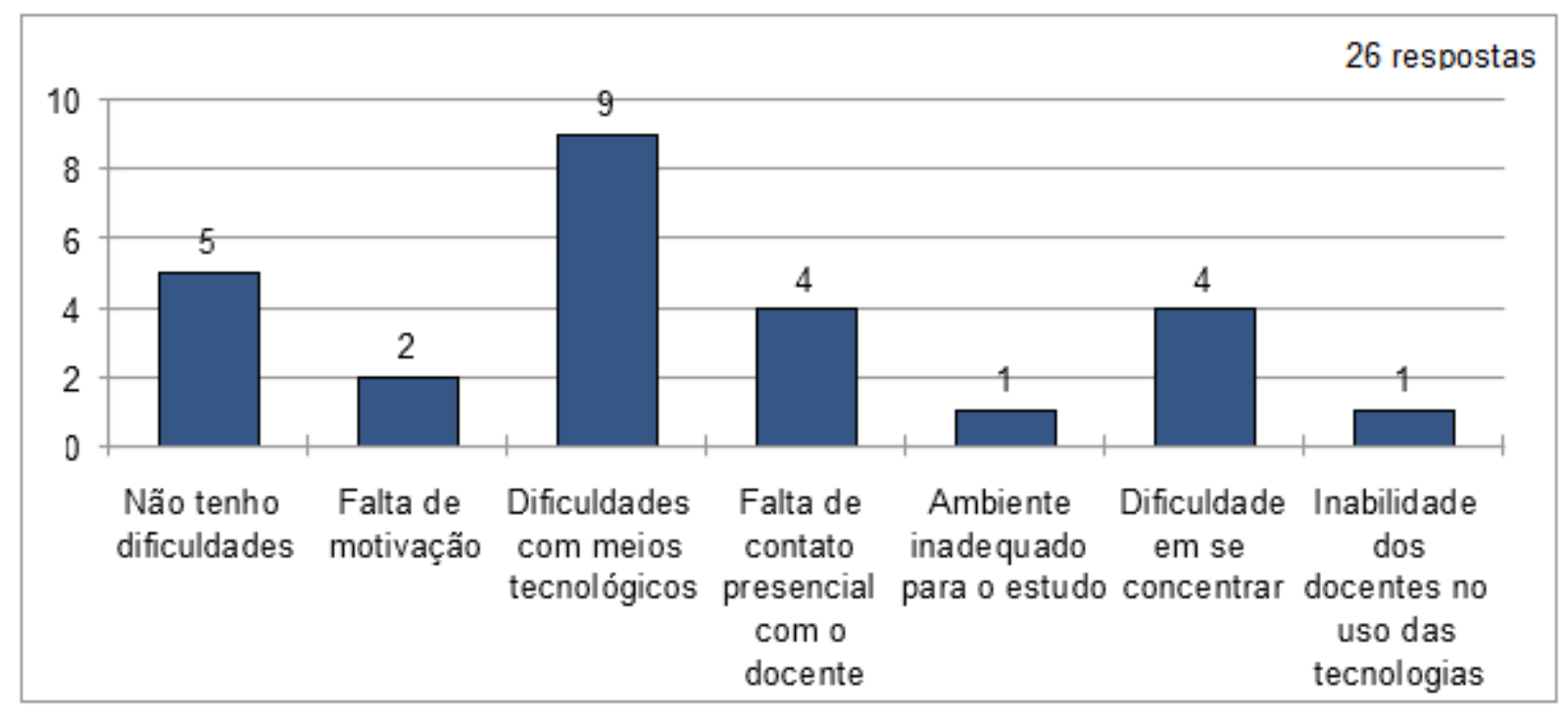

Fonte: Acervo pessoal do autor (2021).

A oitava questão indagou aos discentes em qual momento tiveram o primeiro contato com o conteúdo de Genética. Nas respostas, três alunos (11,5\%) tiveram o primeiro contato no Ensino Fundamental, 20 discentes (77\%) no Ensino Médio e três participantes (11,5\%) tiveram o primeiro contato somente no Ensino Superior. A representação gráfica das respostas pode ser evidenciada na Figura 6.

Carvalho e Vivarini (2021), ao realizarem um trabalho de pesquisa entre os anos de 2015 e 2019 com estudantes de pré-vestibular no município de Petrópolis-RJ, observaram que 72\% dos participantes só tiveram contato inicial com conteúdo de Genética no Ensino Médio, enquanto $11 \%$ não tiveram contato em nenhum momento, e $17 \%$ não lembram de nenhum conteúdo de Genética ministrado durante a Educação Básica

Nossos resultados demonstram que a maioria dos discentes $(88,5 \%)$ participantes da pesquisa não teve contato com os conteúdos de Genética no Ensino Fundamental. Esta realidade se mostra em total desacordo à Base Nacional Comum Curricular (BNCC), ao mencionar que, no $9^{\circ}$ ano do Ensino Fundamental, a disciplina de Ciências deve discutir as ideias de Mendel sobre hereditariedade (fatores hereditários, segregação, gametas, fecundação), considerando-as para resolver problemas envolvendo a transmissão de características hereditárias em diferentes organismos (Brasil, 2018).

Figura 6. Representação gráfica das respostas dos discentes em relação ao seu primeiro contato com os conteúdos de Genética.

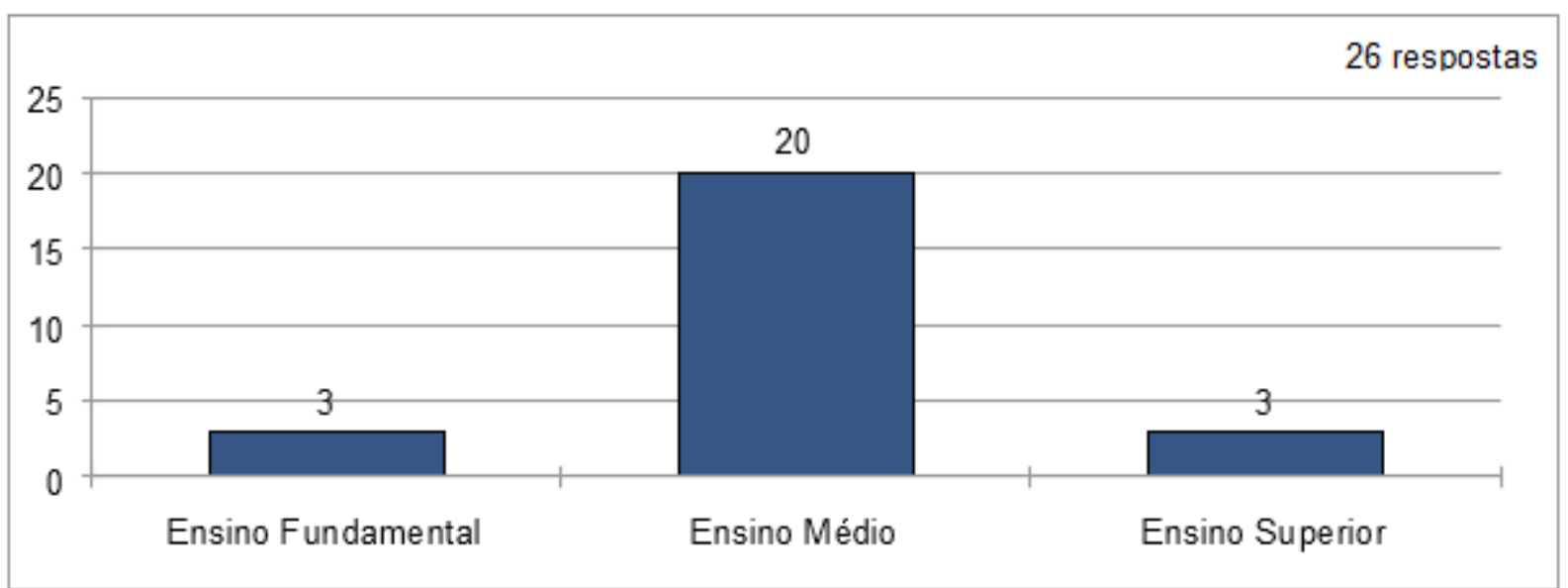

Fonte: Acervo pessoal do autor (2021). 
A nona questão indagou aos discentes se os conteúdos de Genética foram trabalhados adequadamente na Educação Básica. Nas respostas, dois participantes (7,7\%) destacaram que foram bem trabalhados, 11 alunos $(42,30 \%)$ destacaram que foram trabalhados de forma regular e 13 alunos (50\%) destacaram que esses conteúdos foram trabalhados de forma inadequada na Educação Básica, como observado na Figura 7.

Cirne e Costa (2015) afirmam que o processo de formação de conceitos na Genética é demorado e complicado. Mesmo utilizando-se atividades bem desenvolvidas e estruturadas, muitos estudantes ainda não alcançam as fases finais de elaboração dos conceitos científicos relacionadas ao conteúdo da disciplina. Portanto, não trabalhar esses tópicos de forma adequada na Educação Básica, pode ser um dos fatores para as dificuldades observadas em relação aos conteúdos de Genética.

Figura 7. Representação gráfica das respostas dos participantes da pesquisa em relação à forma em que os conteúdos de Genética foram trabalhados na Educação Básica.

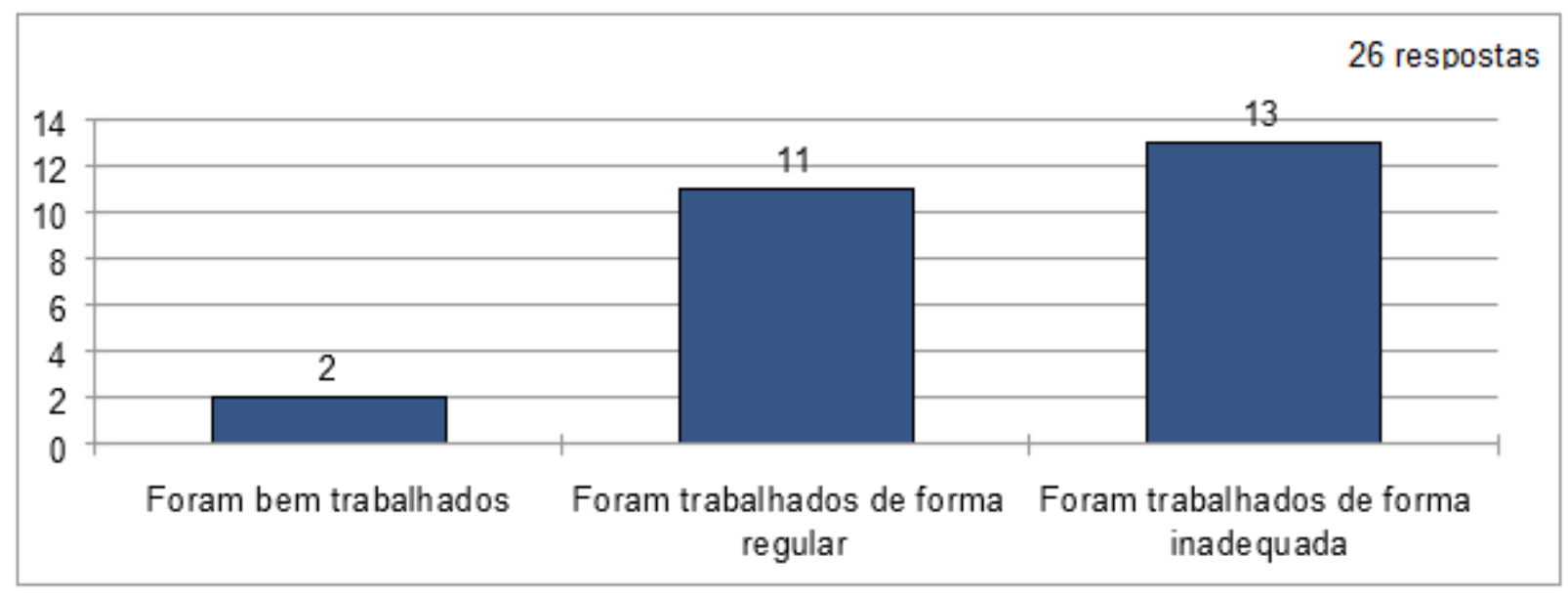

Fonte: Acervo pessoal do autor (2021).

$\mathrm{Na}$ questão 10, indagou-se aos participantes a sua principal dificuldade em relação ao aprendizado no ensino de Genética no curso de Licenciatura em Ciências Biológicas. Nas respostas, 13 estudantes (50\%) relataram, principalmente, a dificuldade na compreensão de termos técnicos, quatro (15,38\%) destacaram a falta de dedicação à disciplina, três $(11,53 \%)$ apontaram as metodologias escolhidas pelo docente da disciplina e um participante $(3,84 \%)$ associou a sua licença médica como principal causa de dificuldade. Cinco alunos $(19,23 \%)$ relataram não ter dificuldades no aprendizado da Genética, como observado na Figura 8.

Silva e Kalhil (2017), ao realizarem uma pesquisa com alunos do curso de Licenciatura em Ciências Biológicas do Instituto Federal do Amazonas (IFAM), evidenciaram que o ensino-aprendizado de Genética envolve vários fatores e que é um conteúdo de difícil compreensão. Eles reforçam ainda a necessidade de alternativas metodológicas na tratativa da Genética. 
Figura 8. Representação gráfica das respostas dos participantes da pesquisa em relação às dificuldades associadas ao aprendizado da Genética no ensino superior.

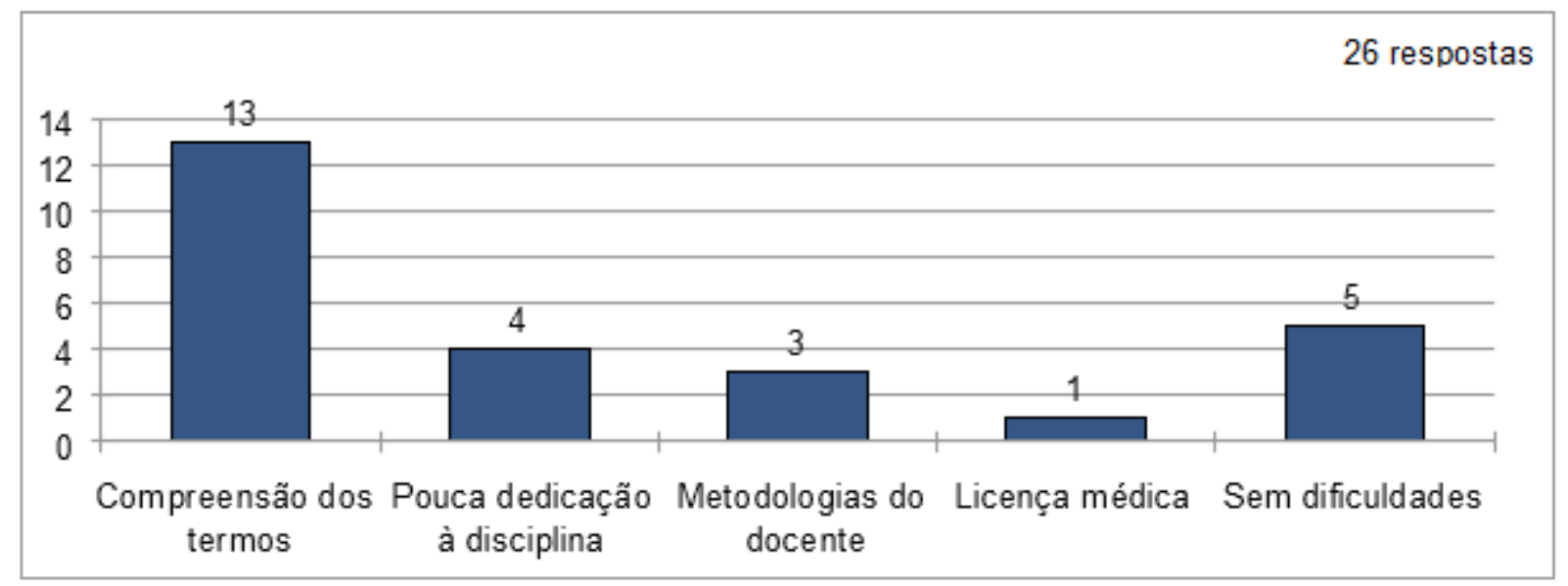

Fonte: Acervo pessoal do autor (2021).

$\mathrm{Na}$ questão 11, avaliou-se a percepção dos discentes quanto aos seus aprendizados em relação à disciplina de Genética, ministrada integralmente de forma remota. Nas respostas, seis alunos (23\%) consideraram seu aprendizado ótimo, seis alunos (23\%) consideraram seu aprendizado regular, e 14 participantes (54\%) consideraram seu aprendizado bom. Nenhum discente marcou a alternativa ruim ou péssimo. Na questão seguinte, perguntou-se aos discentes se eles sentem necessidade de estudar novamente os conteúdos de Genética, e, nas respostas, 24 discentes (92\%) responderam que sim, e dois participantes (8\%) que não.

Nascimento e Meirelles (2016), ao realizarem uma investigação com 115 alunos de quatro escolas públicas do Rio de Janeiro sobre tópicos relacionados à Genética e saúde humana no Ensino Médio, consideraram importante rever conhecimentos e conceitos outrora estudados, assim como introduzir novos conceitos pertinentes, aproximando os estudantes dos saberes científicos, escolares e populares relacionados à Genética. Em contrapartida, Barni (2010) em sua pesquisa com estudantes de $3^{\circ}$ ano do Ensino Médio, aponta que os discentes muitas vezes assumem um estado passivo, esperando que o professor transfira os conhecimentos, não se dedicando a ir em busca de outras formas de aprender.

Foi perguntado aos estudantes na questão 12 se sua universidade possibilitava trabalhos de pesquisa e extensão relacionados à área de Genética. Nas respostas, dois participantes (8\%) responderam que sim, 10 alunos (38\%) responderam talvez, e 14 (54\%) responderam que não. As respostas evidenciam distanciamento dos discentes com pesquisas na área de Genética e, por isso, muitos desses futuros docentes chegam à Educação Básica com dificuldades de aplicar seu conhecimento científico nessa e em outras áreas, sem um aprofundamento e reflexão dos conteúdos de Biologia.

Marin e Vinholi-Junior (2020), ao analisaram teses e dissertações brasileiras entre os anos de 2004 e 2019, vinculados à área do ensino de Genética, apontaram que ainda é substancial a quantidade de publicações e de trabalhos de pesquisas relacionados ao ensino de Genética no Ensino Médio, o que fragiliza todo o processo de ensino-aprendizagem dos discentes, uma vez que a aplicação prática desses conceitos tem influência positiva no aprendizado.

A questão 13 (subjetiva) pediu-se aos participantes sugestões para melhorar a qualidade da disciplina de Genética no seu referido curso. Para melhor compreensão, foi realizada uma análise de conteúdo e as respostas foram distribuídas em seis categorias. Nas respostas, oito participantes (30\%) apontaram mais aulas práticas, seis alunos (23\%) sugeriram diversidade de metodologias, três (12\%) apontam a necessidade de relacionar o ensino ao cotidiano do aluno, um discente sugere melhor visualização dos processos (4\%) e um discente (4\%) propôs a realização de um projeto prático. Sete participantes (27\%) não propuseram nenhuma mudança na disciplina, como observado na Figura 9. Esses dados estão em conformidade com a pesquisa 
realizada por Borges, Silva e Reis (2017), na qual estudantes do Ensino Médio sugeriram metodologias diferenciadas com o uso de recursos didáticos, dinâmicas e ilustrações para tornarem as aulas mais atrativas e interessantes.

Figura 9. Representação gráfica das sugestões dos participantes da pesquisa para melhoria da disciplina Genética no seu curso de Licenciatura.

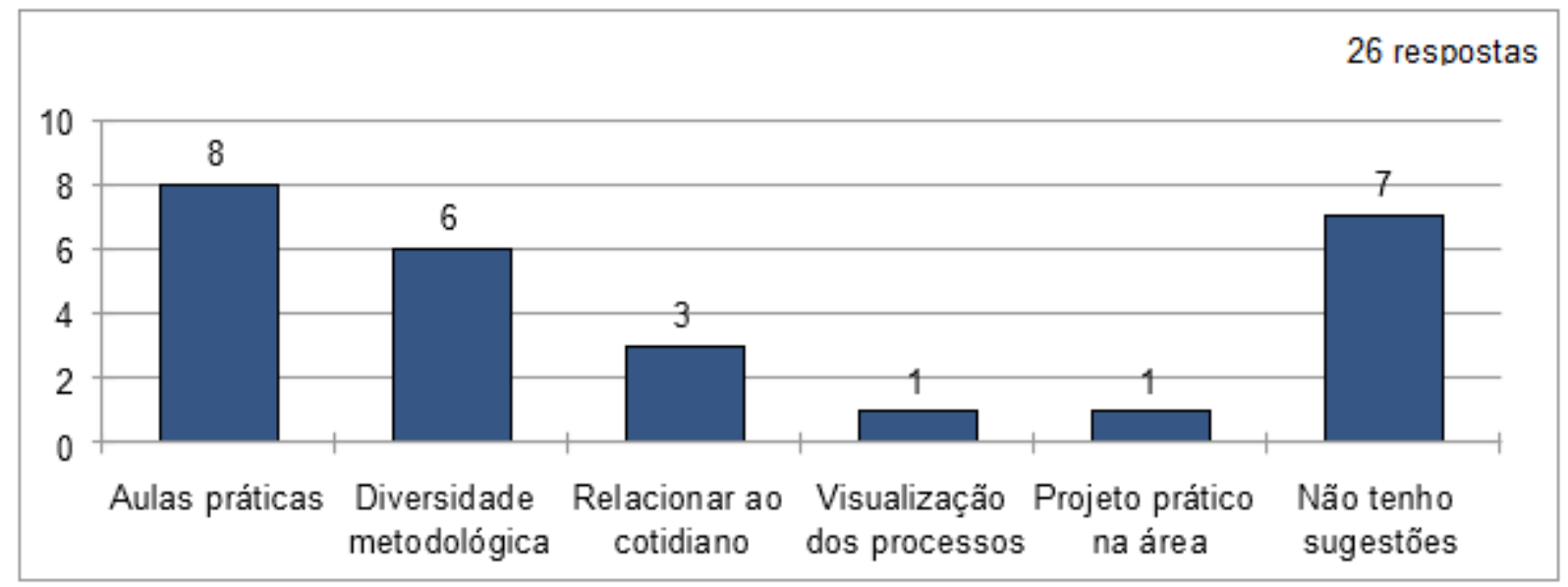

Fonte: Acervo pessoal do autor (2021).

\section{Considerações Finais}

Apesar do ensino remoto se mostrar um desafio, observamos que as principais dificuldades dos discentes, associadas ao ensino de Genética, vêm de carências na tratativa desses conteúdos na Educação Básica e da falta de afinidade dos discentes aos termos técnicos inerentes à disciplina. Além disso, destacamos que a ausência de aulas práticas e projetos no contexto da Genética, inviabilizados na pandemia, são barreiras que dificultam a contextualização dos conteúdos.

Independente do constante esforço de todos os envolvidos no ensino remoto, observa-se ainda forte rejeição dos discentes ao mesmo, bem como obstáculos impostos por essa forma de ensino que ainda não foram superadas pelas instituições educacionais, que influenciam de maneira negativa no rendimento dos estudantes. Por isso, enfatizamos a necessidade da realização de mais estudos que apontem a influência do ensino remoto na formação de docentes brasileiros e dos seus reflexos na qualidade de ensino na Educação Básica.

\section{Referências}

Araújo, M. S., Freitas, W. L. S., Lima, S. M. S., \& Lima, M. M. O. (2018). A Genética no contexto de sala de aula: dificuldades e desafios em uma escola pública de Floriano-PI. Revista de Ensino de Ciências e Matemática, 9(1), 19-30. https://revistapos.cruzeirodosul.edu.br/index.php/rencima/article/view/1300

Barni, G. S. (2010). A importância e o sentido de estudar Genética para estudantes do terceiro ano do ensino médio em uma escola da rede estadual de ensino em Gaspar (SC). 184f. Dissertação (Mestrado Profissional em Ciências Naturais e Matemática) - Universidade Regional de Blumenau, Blumenau, 2010. http://www.uniedu.sed.sc.gov.br/wp-content/uploads/2013/10/Graziela-dos-Santos-Barni.pdf

Borges, C. K. G. D., Da Silva, C. C., \& Reis, A. R. H. (2017). As dificuldades e os desafios sobre a aprendizagem das leis de Mendel enfrentados por alunos do ensino médio. Experiências em Ensino de Ciências, 12(6), 61-75. https://fisica.ufmt.br/eenciojs/index.php/eenci/article/view/661/631

Brasil $^{\text {a }}$ Portaria $n^{\circ} 343$, de 17 de março de 2020. (2020). Dispõe da substituição das aulas presenciais por aulas em meios digitais enquanto durar a situação de pandemia do novo coronavírus - COVID-19. Brasília. DOU - Diário Oficial da União. Publicado em 17 de março de 2020. https://www.in.gov.br/en/web/dou/-/portaria-n-343-de-17-de-marco-de-2020-248564376

Brasil ${ }^{\mathrm{b}}$. Portaria $N^{\circ} 544$, de 16 de junho de 2020. (2020). Dispõe sobre a substituição das aulas presenciais por aulas em meios digitais, enquanto durar a situação de pandemia do novo coronarírus - Covid-19, e revoga as Portarias MEC n ${ }^{\circ} 473$, de 12 de maio de 2020 . DOU - Diário Oficial da União. Publicado em 17 de junho de 2020. https://www.in.gov.br/en/web/dou/-/portaria-n-544-de-16-de-junho-de-2020-261924872

Brasil. Ministério da Educação (2018). Base Nacional Comum Curricular. Brasília, 2018. http://basenacionalcomum.mec.gov.br/images/BNC C_EI_EF_110518_versaofinal_site.pdf 
Carvalho, V. A., \& Vivarini, B. C. D. (2021). Análise do aprendizado de Genética e Biologia Molecular em um pré-vestibular social: um reflexo do Ensino Médio, Revista Educação Pública, 21(9), 1-12, https://educacaopublica.cecierj.edu.br/artigos/21/9/analise-do-aprendizado-de-genetica-e-biologia-molecularem-um-pre-vestibular-social-um-reflexo-do-ensino-medio

Castro, Y. A. A., Silva, J. S. H. G., Pontes, A. R. M. B., Silva, C. H. C., \& Castro, I. F. A. (2021) Período letivo excepcional: perspectivas de discentes de uma instituição federal de ensino pernambucana. International Journal Education And Teaching, 4(1), 188-204. https://ijetpdvl.com/index.php/pdvl/article/view/160

Cirne, A. D. P. P., \& Costa, I. A. S. (2015). Concepções alternativas sobre conceitos de genética no ensino fundamental. Metáfora Educacional, 19(1), 53-79. https://dialnet.unirioja.es/servlet/articulo?codigo $=7067293$

Cordeiro, K. M. D. A. (2020) O Impacto da Pandemia na Educação: A Utilização da Tecnologia como Ferramenta de Ensino. http://idaam.siteworks.com.br/jspui/bitstream/prefix/1157/1/O\%20IMPACTO\%20DA\%20PANDEMIA\%20NA\%20EDUCAÇÃO\%20A\%20UTILIZAÇÃO\% 20DA\%20TECNOLOGIA\%20COMO\%20FERRAMENTA\%20DE\%20ENSINO.pdf

Dosea, G. S., Rosário, R. W. S., Silva, E. A., Firmino, L. R., \& Santos O. A. M. (2020). Métodos ativos de aprendizagem no en sino online: a opinião de universitários durante a pandemia de COVID-19. Interfaces Científicas-Educação, 10(1), 137-148. https://periodicos.set.edu.br/educacao/article/view/9074

Durão, A., \& Raposo, A. Desafios do Ensino Remoto de Emergência. (2020). Interacções, 16(55), 28-40. https://revistas.rcaap.pt/interaccoes/article/view/20999

Feitosa, M. C., Moura, P. D., Ramos, M. S. F., \& Lavor, O. P. (2020). Ensino Remoto: O que Pensam os Alunos e Professores. Anais do V Congresso sobre Tecnologias na Educação, 5(1), 60-68. https://sol.sbc.org.br/index.php/ctrle/article/view/11383

Ferreira, M., \& Loguercio, R. Q. (2014). A análise de conteúdo como estratégia de pesquisa interpretativa em educação em ciências. Revista de Educação, Lingua e Literatura. 6(2), 33-49, 2014. https://www.revista.ueg.br/index.php/revelli/article/view/3006

Flores, M. A., Simão, A. M. V., Barros, A., Flores, P., Pereira, D., Fernandes, E. L., \& Costa, L. (2021). Ensino e aprendizagem à distância em tempos de COVID-19. Um estudo com alunos do Ensino Superior. Revista Portuguesa de Pedagogia, 55(1), 1-28. https://impactumjournals.uc.pt/rppedagogia/article/view/9189

Fontelles, M. J., Simões, M. G., Farias, S. H., Fontelles, R. G. S. (2009). Scientific research methodology: Guidelines for elaboration of a research protocol. Revista Paraense de Medicina, 23(3), 1-8. http://files.bvs.br/upload/S/0101-5907/2009/v23n3/a1967.pdf

Furtado, R. N. (2019). Edição Genética: Riscos e Benefícios da Modificação do DNA Humano. Revista Bioética, 27(2), 223-33. https://www.scielo.br/j/bioet/a/jFptVvKR7RJHWXwmsKpZFrh/?lang=pt\&format=pdf

Gonçalves, M. H. P. (2020). Obstáculos à efetivação do ensino-aprendizagem em Genética: percepções dos alunos do curso de Licenciatura em Ciências Biológicas da UFCG Campus Cajazeiras-PB, 2020. 41f. Trabalho de Conclusão de Curso (Graduação em Ciências Biológicas) - Universidade Federal de Campina Grande, Campina Grande. http://dspace.sti.ufcg.edu.br:8080/xmlui/handle/riufcg/18593

Griffiths, A. J. F., Wessler, S. R., Carroll, S. B., Doebley, J. Introdução à Genética. 11. ed. Rio de Janeiro: Guanabara Koogan; 2016. Tradução: Sylvia Werdmüller von Elgg Roberto. Tradução de: Introduction to Genetic Analysis. https://www.academia.edu/38593258/Introdução_à_Genética_Griffts_11ed

Lander, E. S., Baylis, F., Zhang, F., Charpentier, E., Berg, P., Bourgain, C. et al. (2019). Adopt a Moratorium on Heritable Genome Editing [Adote uma Moratória na Edição do Genoma Hereditário]. Nature, 567(1), 165-168. https://www.nature.com/articles/d41586-019-00726-5?fbclid=IwAR1vyQZwbOrhSBAFxJAF3EP7nqcTpzNJybS-86vFLwrtrX2VnuWJjBt3wU

Lima, N. R. B. S., Silva, J. J. J., \& Coutinho, D. J. G. (2020). Desafios diante da modalidade remota na prática docente frente à pandemia da covid-19. Revista Ibero-Americana de Humanidades, Ciências e Educação, 6(11), 1-11. https://www.periodicorease.pro.br/rease/article/view/212

Marin, G. R. B., \& Júnior, A. J. V. (2020). Produção Científica Sobre O Ensino De Genética No Brasil: Uma Análise De Teses E Dissertações (2004-2019). South American Journal of Basic Education, Technical and Technological, 7(2), 922-944. https://periodicos.ufac.br/index.php/SAJEBTT/article/view/3323

Menezes, J. B. F. (2021). Práticas de avaliação da aprendizagem em tempos de ensino remoto. Revista de Instrumentos, Modelos e Políticas em Avaliação Educacional, 2(1), 1-13. https://revistas.uece.br/index.php/impa/article/view/5384

Moreira, J. A., Henriques, S., \& Barros, D. M. V. (2020). Transitando de um ensino remoto emergencial para uma educação digital em rede, em tempos de pandemia. Dialogia, 34(1), 351-364. https://repositorioaberto.uab.pt/handle/10400.2/9756

Nascimento, J. M., \& Meirelles, R. M. (2015). Conectando saberes e 'superpoderes' para mediar tópicos em genética e saúde no ensino médio. Revista Práxis, 7(14), 47-56. http://revistas.unifoa.edu.br/index.php/praxis/article/view/711/611

Pereira, L. T. K., Godoy, D. M. A., \& Tercariol, D. (2020). Estudo de caso como procedimento de pesquisa científica: reflexão a partir da clínica fonoaudiológica. Psicologia Reflexiva Critica, 22(3), 422-429. https://www.scielo.br/j/prc/a/Rjm8bQcZJjSn4MXZCpNzyLj/abstract/?lang=pt

Ries, E. F., Rocha, V. M. P., \& Silva, C. G. L. (2020). Avaliação do ensino remoto de Epidemiologia em uma universidade pública do Sul do Brasil durante pandemia de COVID-19, Scielo em Perspectiva. Disponivel em: https://preprints.scielo.org/index.php/scielo/preprint/view/1152

Santos, F. S. Programa Neurocientifico para a Aprendizagem Significativa de Genética. (2018). 260f. Tese (Doutorado em Ensino de Ciência e Tecnologia) -

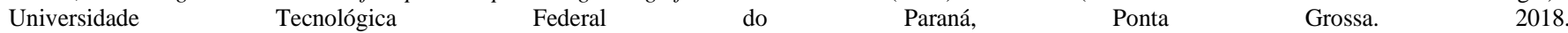
http://riut.utfpr.edu.br/jspui/bitstream/1/3121/1/PG_PPGECT_D_Santos\%2C\%20Fabio\%20Seidel\%20dos_2018.pdf

Santos, F. S., Ferraz, D. F., Klein A. I., De Francisco, A. C., \& Miquelin, A. F. (2020). Sequência didática fundamentada na neurociência para o ensino de genética. Revista Electronica de Enseñanza de las Ciências, 19(2), 359-383. http://reec.uvigo.es/volumenes/volumen19/REEC_19_2_6_ex1612_199F.pdf 
Research, Society and Development, v. 10, n. 9, e28810918088, 2021

(CC BY 4.0) | ISSN 2525-3409 | DOI: http://dx.doi.org/10.33448/rsd-v10i9.18088

Silva, B. M., \& Júnior, M. A. B. (2021). Engajamento e interatividade no Ensino Remoto: A sala de aula digital em tempos de pandemia. Revista Linguagem, Ensino e Educação, 5(2), 36-57. http://periodicos.unesc.net/lendu/article/view/6367

Silva C. C., \& Kalhil J. B. (2017). A aprendizagem de Genética à luz da Teoria Fundamentada: um ensaio preliminar. Ciência \& Educação, 23(1), 125-140. https://www.scielo.br/j/ciedu/a/kq5jc47qxJhtwjXD3Tb6xSq/abstract/?lang=pt 